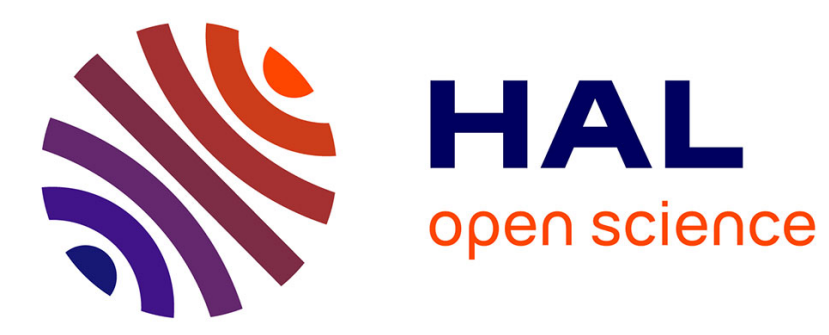

\title{
Ammonia detection by a novel Pyrex microsystem based on thermal creep phenomenon
}

V Martini-Laithier, Irina Graur, Sandrine Bernardini, Khalifa Aguir, Pierre Perrier, Marc Bendahan

\section{- To cite this version:}

V Martini-Laithier, Irina Graur, Sandrine Bernardini, Khalifa Aguir, Pierre Perrier, et al.. Ammonia detection by a novel Pyrex microsystem based on thermal creep phenomenon. Sensors and Actuators B: Chemical, 2014, 10.1016/j.snb.2013.10.120 . hal-01441839

\section{HAL Id: hal-01441839 \\ https://hal.science/hal-01441839}

Submitted on 20 Jan 2017

HAL is a multi-disciplinary open access archive for the deposit and dissemination of scientific research documents, whether they are published or not. The documents may come from teaching and research institutions in France or abroad, or from public or private research centers.
L'archive ouverte pluridisciplinaire HAL, est destinée au dépôt et à la diffusion de documents scientifiques de niveau recherche, publiés ou non, émanant des établissements d'enseignement et de recherche français ou étrangers, des laboratoires publics ou privés. 


\section{Accepted Manuscript}

Title: Ammonia detection by a novel Pyrex microsystem based on thermal creep phenomenon

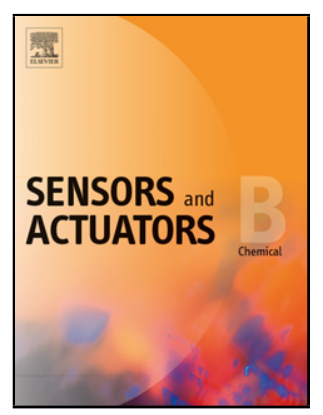

Author: $<$ ce:author id="aut0005" biographyid="vt0005"> V.

Martini-Laithier<ce:author id="aut0010"

biographyid="vt0010"> I. Graur<ce:author id="aut0015"

biographyid="vt0015"> S. Bernardini<ce:author

id="aut0020" biographyid="vt0020" $>$ K. Aguir $<$ ce:author

id="aut0025" biographyid="vt0025"> P. Perrier<ce:author

id="aut0030" biographyid="vt0030"> M. Bendahan

PII:

S0925-4005(13)01322-1

DOI:

http://dx.doi.org/doi:10.1016/j.snb.2013.10.120

Reference:

SNB 16155

To appear in: $\quad$ Sensors and Actuators B

Received date: 23-7-2013

Revised date: $\quad 26-10-2013$

Accepted date: $\quad 29-10-2013$

Please cite this article as: V. Martini-Laithier, I. Graur, S. Bernardini, K. Aguir, P. Perrier, M. Bendahan, Ammonia detection by a novel Pyrex microsystem based on thermal creep phenomenon, Sensors and Actuators B: Chemical (2013), http://dx.doi.org/10.1016/j.snb.2013.10.120

This is a PDF file of an unedited manuscript that has been accepted for publication. As a service to our customers we are providing this early version of the manuscript. The manuscript will undergo copyediting, typesetting, and review of the resulting proof before it is published in its final form. Please note that during the production process errors may be discovered which could affect the content, and all legal disclaimers that apply to the journal pertain. 


\title{
Ammonia detection by a novel Pyrex microsystem based on thermal creep
}

\section{phenomenon}

$\underline{\text { V. Martini-Laithier }}^{1,2}$, I. Graur ${ }^{1,3}$, S. Bernardini ${ }^{1,2}$, K. Aguir ${ }^{1,2}$, P. Perrier ${ }^{1,3}$ and M. Bendahan ${ }^{1,2}$

${ }^{1}$ Aix-Marseille Université, Marseille, France,

${ }^{2}$ CNRS, IM2NP (UMR 7334), Marseille, France,

${ }^{3}$ CNRS, IUSTI (UMR 7343), Marseille, France.

Corresponding author: virginie.martini@im2np.fr

\begin{abstract}
Our research work aims to develop a microfluidic system for gas analysis by using an original principle of integrated pumping. This microsystem can detect ammonia and the gas flow parameters inside the channel can be also controlled. The proposed microdevice consists in a microchannel including an integrated gas sensor with a heater. The trioxide tungsten $\left(\mathrm{WO}_{3}\right)$ is implemented as a sensitive layer. The integrated heater is used for two reasons: to optimize the sensor response and to induce the gas pumping inside the microchannel by thermal creep phenomenon, therefore, no external pumping system is required. The study of the pumping effect generation has been realized by thermal and microfluidic simulations. Thermal simulations have been performed to estimate the thermal gradient along the microchannel. In addition, the microfluidic modelling allows us to determine the mass flow rate for different thermal gradient profiles, obtained from the thermal simulations. Finally, a complete Pyrex microsystem has been realized to detect ammonia. The existence of the thermal pumping has been demonstrated experimentally.
\end{abstract}

Key words: Gas sensor, Gas pumping, Thermal creep, Microfluidic, Gas detection, $\mathrm{WO}_{3}$ 


\section{Introduction}

All control laboratories manipulate constantly standard gas analyzers for the atmospheric pollutant controls. These devices are precise to determine the concentration and the nature of gas samples, but they are bulky, slow, and very expensive. The development of microfluidic systems could be the solution to avoid the standard analyzer disadvantages.

Several devices are developed to improve the sensitivity of the microsystems for gas analysis. The authors of Ref. [1] have developed new chromatographic microcolumns which lead to enhance the selectivity including VOC (volatile organic compounds) separation [1-3]. Many researches on preconcentrator realisation allow improving the sensitivity by increasing the gas concentration before detection $[1,4,5]$. Other researchers [5-7] use microreactors to modify the gas nature in order to increase the detection sensitivity. But all these systems need sampling or external pump to analyze gas.

Our work targets to develop and to test new microdevice for gas detection with an integrated pumping system to sample a pollutant before detection. This microsystem is composed of a metal oxide base sensor, which includes a platinum heater. This heater is used for two reasons: to optimize the sensor response and to create a temperature gradient along the channel surface and therefore the thermal creep phenomenon. The presence of the temperature gradient along the channel's surface launches the macroscopic gas movement inside microchannel, from the cold side to the hot side.

In this paper, we present the thermal creep phenomenon. This phenomenon has some technological applications such as a new pump without any moving parts [6], or gas separation process in gas chromatography [7]. Then, we justify the choice of the microsystem's dimensions and the values of applied temperature gradient along their surfaces 
for gas transport inside the microsystem. Next, through the thermal simulation the best channel material is determined in order to assure the large enough temperature gradient along the channel's walls. The microfluidic simulation allows us to determine the mass flow rates through the microsystem. Finally, the details of the fabrication steps are given and the experimental results for ammonia detection are discussed.

\section{Microfluidic model study}

\subsection{Thermal creep phenomenon}

Reynolds has discovered the thermal creep phenomenon in 1878 showing the macroscopic movement of rarefied gas from the lower to the higher temperature zone. Indeed, when two reservoirs connected by a microchannel are maintained continuously at different temperatures and at the same pressure, a gas flows from the cold to the hot reservoirs (Fig. 1). The gas rarefaction is characterized usually by the ratio between a molecular mean free path and a characteristic scale of the problem; this ratio is called the Knudsen number. A characteristic dimension of a microdevice is of the order of several micrometers, therefore a gas inside is rarefied (the Knudsen number is larger than 0.01) even at atmospheric pressure. In presence of a thermal gradient inside the microdevices a gas displacement can be obtained in the gradient direction.

Recently, the mass flow rate through a micro-tube generated by the temperature gradient was measured in [8-9] for several gases and various temperature differences. It was shown that the mass flow rate induced by the temperature gradient is proportional to the temperature gradient intensity. This mass flow rate depends also on the gas rarefaction, characterized by the Knudsen number, and so proportional to the characteristic scale of the problem. Therefore 
it is possible to adjust and to control the mass flow rate by modifying the thermal gradient intensity along the channel's surface or the geometrical characteristics of the microdevice.

In the present study we use the thermal creep phenomenon to obtain the gas flow through a microchannel, where a sensor is integrated. Two open ends of the microchannel are maintained naturally at the atmospheric pressure and a heater integrated in one of channel's surfaces provides the temperature gradient. This heater is also used to increase the detection response performance.

\subsection{Model}

Our microsystem is composed of two parts: a support (A) and a cover (B) (Fig. 2). The support contains the platinum electrodes for electrical measurements, the metal oxide sensitive film $\left(\mathrm{WO}_{3}\right)$ and the platinum resistive heater device. The microchannel has a rectangular cross section with height $\mathrm{h}$ and width 1 , the microchannel length is equal to $\mathrm{L}$, represented in Fig. 2. The cover contains the etched microchannel in which the sensor is inserted.

The sensor required to be heated for its detection performance. This sensor heating is also used to create the high thermal gradient inside the microchannel, which is essential for the gas pumping. In order to obtain this thermal creep phenomenon the control of two parameters are required: the gas flow regime inside the channel (slip regime) and the temperature difference between the two channels ends [10].

The slip regime corresponds to a Knudsen number between $10^{-3}$ and $10^{-1}$. As it was explained in Section 2.1, in order to obtain the slip flow regime [10] inside the channel under atmospheric conditions, the channel height (characteristic scale of our case) was chosen to be equal to $10 \mu \mathrm{m}$. The microchannel width was chosen to be equal to $500 \mu \mathrm{m}$ to insert the 
microsensors inside the microchannel extremity. The length choice was linked both to the value of the temperature gradient wished and to the flow rate estimation. All these dimensions are chosen to obtain the best microsystem performances [11].

\subsection{Thermal gradient simulations}

Comsol Multiphysics software is used to determine the temperature gradient profile along the microchannel (Fig. 3) and it allows us to choose the best (in view of thermal properties) material for the substrate and for the cover.

We tested two materials with different thermal properties (silicon and Pyrex, compatibles with microtechnology processes). A geometric model (Fig. 3) was drawn from the previously chosen dimensions. The substrate was defined as a simple block of $700 \mu \mathrm{m}$ thickness including the platinum heater. The electrical and thermal parameters, used to create this new sensor model, are more reliable and improve our previous model [11] where these parameters have not been adjusted by the simulations.

In our present sensor model the heater is a thin film of platinum. The setting its thermal properties is one of the most important steps. The principal properties, which characterize the platinum layer, are the electric conductivity $(\sigma)$ and the thermal conductivity $(\lambda)$. These parameters are related through the Wiederman-Franz equation (eq. 1):

$\frac{\lambda}{\sigma}=\frac{\pi^{2}}{3}\left(\frac{\mathrm{k}_{\mathrm{B}}}{\mathrm{e}}\right)^{2} \mathrm{~T}=\angle \times \mathrm{T}$

where $\lambda$ is the thermal conductivity, $\sigma$ is the electric conductivity, $k_{B}$ is the Boltzmann constant, $\quad e$ is the elementary electron charge and $\angle$ is the Lorentz number (eq. 2 ) :

$$
\angle=\frac{\pi^{2} \mathrm{k}_{\mathrm{B}}{ }^{2}}{3 \mathrm{e}^{2}}=2.45 .10^{-8} \mathrm{~W}^{*} \Omega * \mathrm{~K}^{-2}
$$


The platinum layer was deposited by magnetron sputtering to obtain a thickness of 80 nm. Previous tests allowed us to determine experimentally the electric conductivity value of the platinum layer depending of the temperature [12]. The corresponding thermal conductivity values are calculated from these experimental results on the electric conductivity using eq. (1). These values, used for the platinum heater model, are presented in Table 1 for various temperatures [13]. The difference between the bulk thermal conductivity values and our results is explained by the fact that we work with thin Pt films. The experimental data on the thermal conductivity of the platinum layer are used to simulate the thermal behaviours of the microsystem.

We studied the effect of the material properties for the sensor's support and then for the cover of the microsystem model using Comsol Multiphysics software. The first material studied was the silicon, which presents an important thermal conductivity $\left(82.3 \mathrm{~W}^{*} \mathrm{~m}^{*} \mathrm{~K}^{-1}\right.$ at $473 \mathrm{~K})$. The second one was the Pyrex, which has a low thermal conductivity $\left(1.4 \mathrm{~W}^{*} \mathrm{~m}^{*} \mathrm{~K}^{-1}\right.$ at 473K). In the first case these simulation results highlight that the high silicon thermal conductivity induced too important thermal losses to obtain a sufficient temperature gradient for all tested temperatures. In the second case, an important temperature gradient along the Pyrex substrate can be obtained. Thus, Pyrex was chosen to the microsensor support [11].

We also used Comsol Multiphysics software to determine the cover material: Pyrex or silicon. The complete geometry including the microchannel was drawn and added to the Pyrex support. The cover was defined first in silicon then in Pyrex. An important thermal gradient was obtained for each case considering the temperature value along the $\mathrm{x}$-axis direction, see Figure 4. But for Pyrex cover, the temperature decreases regularly along the microchannel and the thermal gradient is higher than for the silicon cover, as it is shown in Figure 4. 
To understand the influences of both the temperature difference at the channel ends and of the temperature gradient along the channel on the gas mass flow rate the microfluidic simulations were performed. By fitting these temperature gradient profiles we found the best equation describing the temperature variations along the microchannel surface (axe $\mathrm{x}$ in Fig. 3). Then, this information about the temperature distribution was used as the boundary conditions in the microfluidic model.

\subsection{Gas mass flow rate simulations}

In order to estimate the mass flow rate through the microchannel, the numerical simulations were carried out using the compressible Navier-Stokes equations subjected the velocity slip and temperature jump boundary conditions [14]. The microchannel is defined as a large rectangular channel connecting two reservoirs. The Knudsen number is fixed in the range $\left[10^{-3} ; 10^{-2}\right]$ and the same pressure is set in the both reservoirs to simulate the open into atmospheric pressure ends of the microdevice. The temperatures in both reservoirs and the temperature distribution along the channel's surfaces are taken from the thermal simulations described in the Section 2.3. Two materials, with different thermal properties, are studied for the channel cover: silicon and Pyrex. The temperature distributions obtained from the simulations with both materials are used as the boundary conditions for the microfluidic part for three heater temperature, see Table 2.

For the lower temperature of the heater, the mass flow rates through the channels with silicon and Pyrex covers have the similar values. However, when the heater temperature increases up to $623 \mathrm{~K}$ the mass flow rate through the channel with Pyrex cover is 1.5 larger than for silicon cover. 
The temperature distributions of the channel's cover in the case of Pyrex and silicon, obtained from thermal modelling and used in the fluidic simulation are shown on Fig. 4. In the case of the silicon cover, the sudden temperature decrease and the small thermal gradient along the channel is not sufficient in order to provide the suitable gas circulation inside the microdevice. However, the Pyrex cover provides more important temperature gradient along the channel's cover (see Fig. 4) and therefore allows creating the more important gas flow rate through the channel, which leads to the better quality of the pollution analysis.

\section{Experiments and discussion}

\subsection{Microsystem realization}

The microsystem was realized with two Pyrex wafers. The wafers 1 and 2 are used to realize the support and the cover, respectively. The microsensors were deposed on the support. They are composed of platinum electrodes, platinum heater and a tungsten trioxide sensitive layer. The platinum layer thickness is $100 \mathrm{~nm}$ and was deposited by magnetron sputtering. Then $\mathrm{WO}_{3}$ layer has a thickness of $80 \mathrm{~nm}$ and was deposited by reactive magnetron sputtering with an argon/oxygen mixture with ratio equal 1 [15]. A very thin titanium layer had been deposed before the platinum to enhance the adhesion on the Pyrex. To finish, the layers were annealed at $673 \mathrm{~K}$ during $1 \mathrm{~h} 30$.

The microchannel is etched into the cover. The Pyrex is a very strong material thus the ultrasound etching were used to cross through the wafer of $1000 \mu \mathrm{m}$ and to define the windows allowing access to microsensors pads. Then, the microchannel has been etched by HF etching for a depth of $10 \mu \mathrm{m}$. 
To obtain the complete microsystem both wafers were bonded together by a technique similar to the thermo-compression performed at ambient temperature. A gold layer was deposed by rf sputtering magnetron on the cover wafer with a chrome adhesion layer. A gold layer was also deposed on the support wafer using a silicon shadow mask, which protects the microsensors. Then, these layers were quickly associated under primary vacuum. A high force of $4000 \mathrm{~N}$ was applied to bond the wafers. The bonding was improved with a hydraulic compression.

\subsection{Microsensor ammonia response (microsensor alone without cover)}

Gas detection was studied first with the gas sensor alone. The sensor performances were tested under diluted gases in dry air, at atmospheric pressure. The normalized sensor response was defined as $S=R_{0} / R_{\mathrm{g}}$, where $R_{0}$ and $R_{\mathrm{g}}$ are the sensor resistances in dry air and in target gas, respectively. We studied $\mathrm{NH}_{3}$ detection at $25 \mathrm{ppm}$ corresponding to the maximum level authorized at the working place and an ammonia sensor must clearly detect partial pressures significantly below this point.

In order to check the effect of operating temperature on the sensor response the microsensor alone has been tested through ammonia gas with several working temperatures from $423 \mathrm{~K}$ to $523 \mathrm{~K}$.

To determine the best work temperature, we measured the detection response and the recovery time with a fixed ammonia concentration. The recovery time is defined as the time to reached $80 \%$ of the origin resistance $\mathrm{R}_{0}$ after ammonia turn off. Figure 5 illustrates the response to $25 \mathrm{ppm}$ of ammonia versus operating temperature. It shows a systematic response increase with increasing operating temperature up to $443 \mathrm{~K}$, but reverse tendency is observed above $443 \mathrm{~K}$. We can also notice that the recovery time decreases when temperature increases. 
The response and recovery time are directly related to the adsorption and desorption activation energies, respectively.

This behaviour can be explained by considering the temperature dependence coverage surface of chemisorbed species [18]. At low temperature, desorption phenomenon is weak and a total coverage of the sites can be obtained easily making no reversible detection possible. Conversely, at high temperature the efficiency of desorption mechanism increases and the system will be less sensitive. The coverage decreases with increasing temperature because the desorption rate rises faster than the adsorption rate. Thus, there is necessarily an optimum temperature at which the sensor reaches a maximum of sensitivity [19-20]. The best response is measured at $443 \mathrm{~K}$, but at this temperature the gas desorption kinetic is slow, which implies a high recovery time. At $523 \mathrm{~K}$ the recovery time is short enough, but the response is lower. We evaluated that the most adapted temperature would be between $463 \mathrm{~K}$ and $493 \mathrm{~K}$, then, we have finally chosen $473 \mathrm{~K}$ as the best compromise between a good sensitivity and fast recovery time.

\subsection{Global microsystem gas characterization (microsensor with cover)}

Remind that the aim of our project is to create a thermal pumping into the microchannel and detect the gas in the generated flow.

The microsystem with Pyrex cover is placed into the detection chamber. The sensor is heated at a temperature of $473 \mathrm{~K}$ to optimize the ammonia detection, as it was explained in the end of previous Section. The gas is led by a nozzle into the microchannel input, i.e. in the opposite extremity of the heated gas sensor. The gas flow rate in the nozzle is $200 \mathrm{ml} / \mathrm{min}$. The microsystem is exposed at ammonia concentration of $50 \mathrm{ppm}$ to forecast a visible response. 
The results show an electrical response corresponding to the ammonia detection. Moreover, this response is reversible after dry air exposure. The microsensor tests have demonstrated that the recovery time is the longest one at this temperature. The gas flow rate and the microchannel volume are also low and amplify this phenomenon. These results demonstrate the possibility to detect ammonia with our microsystem; nevertheless, the electrical response is not sufficient to prove the gas pumping existence from the microchannel entrance to the microsensor. To prove it we have realised a specific detection cell (Fig. 6). The cell's volume is around $8 \mathrm{ml}$. The gas goes into the gas cell and leaves the cell by a natural evacuation. The pressure equilibrium is conserved. The microsystem is placed between the cell and the outside. The microchannel output is placed outdoor of the cell and can exchange directly with the detection chamber. The microchannel input is indoor the cell.

The microsensor is biased and heated and then a pollutant flow is led into the cell. The sensitive layer resistance is measured to detect the ammonia through the microchannel gas flow. In this way, if the microsensor responds to the target gas, we can conclude that a gas flow exists in the microsystem and that the thermal pumping is efficient. We fixed the sensor's temperature at $473 \mathrm{~K}$. The ammonia was injected continuously in the cell. After several seconds an important resistance variation was measured. The total response time corresponds to the sensor response time ( $2 \mathrm{sec} \max )$ and the characteristic time of gas flowing microchannel. At this heater temperature the gas mass flow rate through the channel was evaluated at $2.4710^{-12} \mathrm{~kg}^{*} \mathrm{~s}^{-1}$ (Tab. 2) and therefore the gas characteristic time is of the order of $10 \mathrm{sec}$. An example of the electric signal is presented in Figure 7.

These detections proved the existence of the thermal pumping into the microsystem. 


\section{Conclusion}

The thermal and microfluidic studies let us estimate the best materials for our gas sensor microsystem. Using Comsol Multiphysics software, simulations were done to evaluate thermal gradient along the microchannel. The thermal simulations confirmed the temperature gradient existence required for the thermal creep phenomenon. Microfluidic simulations indicated that Pyrex is the best material for both the substrate and the channel cover. The cover was realized with Pyrex and experimental tests were performed to validate the model. Then, gas detection experiments with the $\mathrm{WO}_{3}$ microsensor demonstrated a high response for the ammonia detection between $423 \mathrm{~K}$ and $523 \mathrm{~K}$ with an optimal work temperature around 473K. The ammonia detection possibility has been confirmed by the microsystem tests at 473K. This measurement is due to the thermal pumping existence demonstrated by the use of the fluidic cell. The future works goal to test interfering gas detections and to improve the selectivity of the microsystem using a channel network.

\section{Acknowledgements}

The authors gratefully acknowledge for financial support in their research by the funding from "Region PACA - BDE n ${ }^{\circ} 648$ " and "Seres Environnement" company and from European Community's Seventh Framework Program (ITN - FP7/2007-2013) under grant agreement $n^{\circ}$ 215504. We would like to thank the MIMENTO Technological Center of Besançon and particularly Fabien AMIOT who was actively involved at the technological realization and A. Combes (Im2np) for technical support. 


\section{References}

[1] S-I. Ohira, K. Toda, Micro gas analyzers for environmental and medical applications, Analytica Chimica Acta 619 (2008) 143-156.

[2] J.-B. Sanchez, F. Berger, M. Fromm, M.-H. Nadal, Use of a chromatographic column to improve the selectivity of the $\mathrm{SnO}_{2}$ gas sensors: first approach towards a miniaturised device and selective with hydrogen fluoride vapours Sensors and Actuators B $106(2005)$ 823-831.

[3] H. Chang, S.K. Kim, T, Sukaew, F. Bohrer, E. Zellers, Microfabricated Gas Chromatograph for Sub-ppb Determinations of TCE in Vapor Intrusion Investigations Procedia Engineering 5 (2010) 973-976.

[4] D. Erickson, D. Li, Integrated microfluidic devices Analytica Chimica Acta 507 (2004) 11-26.

[5] L. Zhu, D. Meier, Z. Boger, C. Montgomery, S. Semancik, D.L. DeVoe, Integrated $\underline{\text { microfluidic gas sensor for detection of volatile organic compounds in water, Sensors }}$ and Actuators B 121 (2007) 679-688.

[6] N. K. Gupta, Y.B Gianchandani, Thermal transpiration in zeolites: A mechanismfor motionless gas pumps, Applied Physics Letters 93, 19 (2008) 193511-193513.

[7] H. Sugimoto, M. Hibino, Numerical analysis on gas separator with thermal transpiration in micro channel, 28th International symposium on rarefied gas dynamics, AIP Conf. Proc. 1501 (2012) 794-801.

[8] M. Rojas, I. Graur, P. Perrier, J.G. Meolans, Thermal transpiration flow: A circular cross-section micro-tube submitted to a temperature gradient, Physic of Physic Letters $23 n^{\circ} 3(2011)$ 031702:1-4. 
[9] M. Rojas, I. Graur, P. Perrier, J.G. Meolans, Time-dependent experimental analysis of a thermal transpiration rarefied gas flow, Physic of Fluids 25 (2013) 072001.

[10] Y. Sone, Flows Induced by Thermal Fields, in: Birkhauser (Eds), Molecular gas dynamics: theory, techniques, and applications, Boston (2007) 233-280.

[11] V. Martini, S. Bernardini, M. Bendahan, K. Aguir, P. Perrier and I. Graur, Fabrication and characterization of gas detection microfluidic system, Procedia Engineering 5 (2010) 1188-1191.

[12] V. Martini, S. Bernardini, M. Bendahan, K. Aguir, P. Perrier and I. Graur, Microfluidic gas sensor with integrated pumping system, Sensors and Actuators B (2010) 45-50.

[13] J. Taine, E. Iacona, J.P. Petit, Transferts Thermiques : Introduction aux transferts d'énergie. Dunod, 2008.

[14] J.G. Méolans, I. Graur, Continuum analytical modelling of thermal creep, European Journal of Mechanics B/Fluids 27 (2008) 785-809.

[15] N. Barsan, U. Weimar, Conduction model of metal oxide gas sensors, Journal of Electroceramics 7 (2001) 143-167.

[16] K. Wetchakun, T. Samerjai, N. Tamaekong et al., Semiconducting metal oxides as sensors for environmentally hazardous gases, Sensors and Actuators B 160 (2011) $580-591$.

[17] M. Epifani, T. Andreu, C. R. Magaña, et al., From doping to phase transformation: Ammonia sensing performances of chloroalkoxide-derived $\mathrm{WO}_{3}$ powders modified with chromium, Sensors and Actuators B 148 (2010) 200-206. 
[18] J. Guérin, K. Aguir, M. Bendahan, C. Mauriat, Thermal modelling of a $\mathrm{WO}_{3}$ ozone sensor response, Sensors and Actuators B 104 (2005) 289-293.

[19] J. Guérin, K. Aguir, M. Bendahan, Modeling of the conduction in a $\mathrm{WO}_{3}$ thin film as ozone sensor, Sensors and Actuators B 119 (2006) 327-334.

[20] M. Bendahan, J. Guérin, R. Boulmani, K. Aguir, $\mathrm{WO}_{3}$ sensor response according to operating temperature: Experiment and modeling, Sensors and Actuators B 124 (2007) 24-29. 


\section{Author Biographies}

Virginie Martini-Laithier is a lecturer at Aix-Marseille University (France). She received her PhD in 2012 at the Aix Marseille University. Since 2008, she has been with the Sensors group at the Institute of Materials, Microelectronics and Nanoscience of Provence (IM2NP). The research performed within the framework of her thesis concerned thermal simulations and microfluidic gas sensor fabrication and characterisation. Her current work involves smoke detection study.

Sandrine Bernardini is a lecturer at Aix-Marseille University (France). She received i) her M.S. degrees in fundamental physics from Paul Cezanne University, Marseille, France in 1999, ii) her Engineering degree in materials and microelectronics from the National Institute of Applied Sciences (INSA), Lyon, France, in 2001, and iii) her Ph.D. degree in microelectronics from Provence University, Marseille, in 2004. From 2005 to 2007, she moved to the Microelectronic and Nanostructure at the University of Manchester (UK), where she was involved in structural and electrical characterizations to study reliability, interface degradation and impact of high-k dielectrics on carrier transport in MOSFETs. From 2007 to 2008, she characterized nanometric systems based on zinc oxide nanorods at the Nanoscience Center of Marseille (CINaM). In 2008, she joined the Sensors Group as Lecturer at the Institute Materials and Microelectronic Nanoscience of Provence (IM2NP). Her current interests and activities cover the engineering and physics of gas sensors and selectivity enhancement strategies.

Marc Bendahan is a Professor at Aix-Marseille University (France). He works in the Sensors Group at the Institute Materials and Microelectronic Nanoscience of Provence (IM2NP). He is also a Lecturer in electronics at the Institute of Technology of Marseille. He was awarded 
his $\mathrm{PhD}$ degree from the University of Aix-Marseille in 1996 with a thesis on shape memory alloys thin films. He is specialized in thin films preparation and characterization for applications in microsystems. Since 1997, he is interested in gas microsensors based on inorganic and organic materials.

Khalifa Aguir is a Professor at Aix Marseille University (France). He was awarded his Doctorat d'Etat ès Sciences degree from Paul Sabatier University, Toulouse (France) in 1987. He is currently the head of Microsensors Group at the Institute of Materials Microelectronic Nanosciences of Provence (IM2NP-CNRS) at Aix-Marseille University, Marseille (France). His principal research interests are now directed towards metal - oxide $\left(\mathrm{WO}_{3}, \mathrm{SrTiO}_{3}, \mathrm{CuO}\right)$ and organic thin films for gas sensors, flexible gas sensors, microsystems, selectivity enhancement strategies including surface modification of sensors, signal treatment, adsorption - desorption noise spectroscopy, modeling of sensor responses analysis, low noise amplifier Design and sensor electronics.

Pierre Perrier received his $\mathrm{PhD}$ from Provence University, France, in 1998. He became research engineer in the French National Center of Scientific Research (CNRS) at Provence University, France in 1999. His current research interests include instrumentation, signal treatment, bio-mecanic, and gas microfluidic experimentations (low and high speed flows).

Irina Graur is a Professor at Aix Marseille University (France). She studied in the Department of Computational Mathematics \& Cybernetics from Moscow State University, where she received her master degree in 1984 and $\mathrm{PhD}$ in 1989. From 1989 to 1990, she was junior researcher at Keldysh Institute of Applied Mathematics USSR Academy of Sciences. She joined the Institute for Mathematical Modeling Russian Academy of Sciences where she 
was researcher from 1990 to 1994 and Senior Researcher from 1994 to 2002. Then, she moved to France as Associate Professor at Polytechnique University School of Marseille at Provence University, and appointed professor in 2009 at Mediterranean University in Marseille, France. Her current research interests include rarefied gas dynamics, High-speed flows, Micro flows, numerical simulations, No-equilibrium and non-stationary flow regimes. 


\section{$\underline{\text { Tables : }}$}

Table 1: Standard and measured thermal and electrical conductivities of platinum, at different temperatures.

Table 2: Mass flow rate calculated for both covers. 
Table 1

\begin{tabular}{|c|c|c|c|}
\hline $\mathbf{T}(\mathbf{K})$ & $\begin{array}{l}\text { Thermal conductivity } \\
\left(\mathrm{W} \cdot \mathrm{m} \cdot \mathrm{K}^{-1}\right) \\
\text { Platinum bulk }\end{array}$ & $\begin{array}{l}\text { Electrical conductivity } \\
\text { (S.m) } \\
\text { Thin platinum film } \\
\text { (experimental values) }\end{array}$ & $\begin{array}{l}\text { Thermal conductivity } \\
\text { (W.m. } \mathrm{K}^{-1} \text { ) } \\
\text { Thin platinum film } \\
\text { (experimental values) }\end{array}$ \\
\hline 293 & 71.5 & $3.8410^{6}$ & 27.5 \\
\hline 373 & 71.5 & $3.2910^{6}$ & 30.0 \\
\hline 473 & 72 & $2.7810^{6}$ & 32.2 \\
\hline 573 & 72.8 & $2.4110^{6}$ & 33.9 \\
\hline 673 & 73.8 & $2.2610^{6}$ & 35.1 \\
\hline
\end{tabular}


Table 2

\begin{tabular}{|c|c|c|c|}
\hline Heater temperature $(\mathrm{K})$ & $\mathbf{4 7 3}$ & $\mathbf{5 7 3}$ & $\mathbf{6 2 3}$ \\
\hline Mass flow rate with a & 2.42 & 3.90 & 4.69 \\
silicon cover $\left(\mathbf{1 0}^{-12} \mathrm{kg.s^{-1 }}\right)$ & & 5.53 & 7.12 \\
\hline Mass flow rate with a & 2.47 & & \\
\hline
\end{tabular}




\section{Figures :}

Figure 1: Thermal creep principle.

Figure 2: Microsystem description: support with microsensor (A) and cover with the microchannel (B).

Figure 3: Our microsystem simulated by Comsol Multiphysics software: Axe X and direction of the thermal gradient.

Figure 4: Profiles of the thermal gradient simulated along the microchannel from the heater to the microchannel input for a pyrex cover (full line) and a silicon cover (dotted line).

Figure 5: Response and recovery time temperature dependence (25 ppm of $\left.\mathrm{NH}_{3}\right)$.

Figure 6: Detection cell.

Figure 7: Pyrex microsystem response for $50 \mathrm{ppm}$ ammonia detection at $473 \mathrm{~K}$ in the detection cell. 
Figure 2

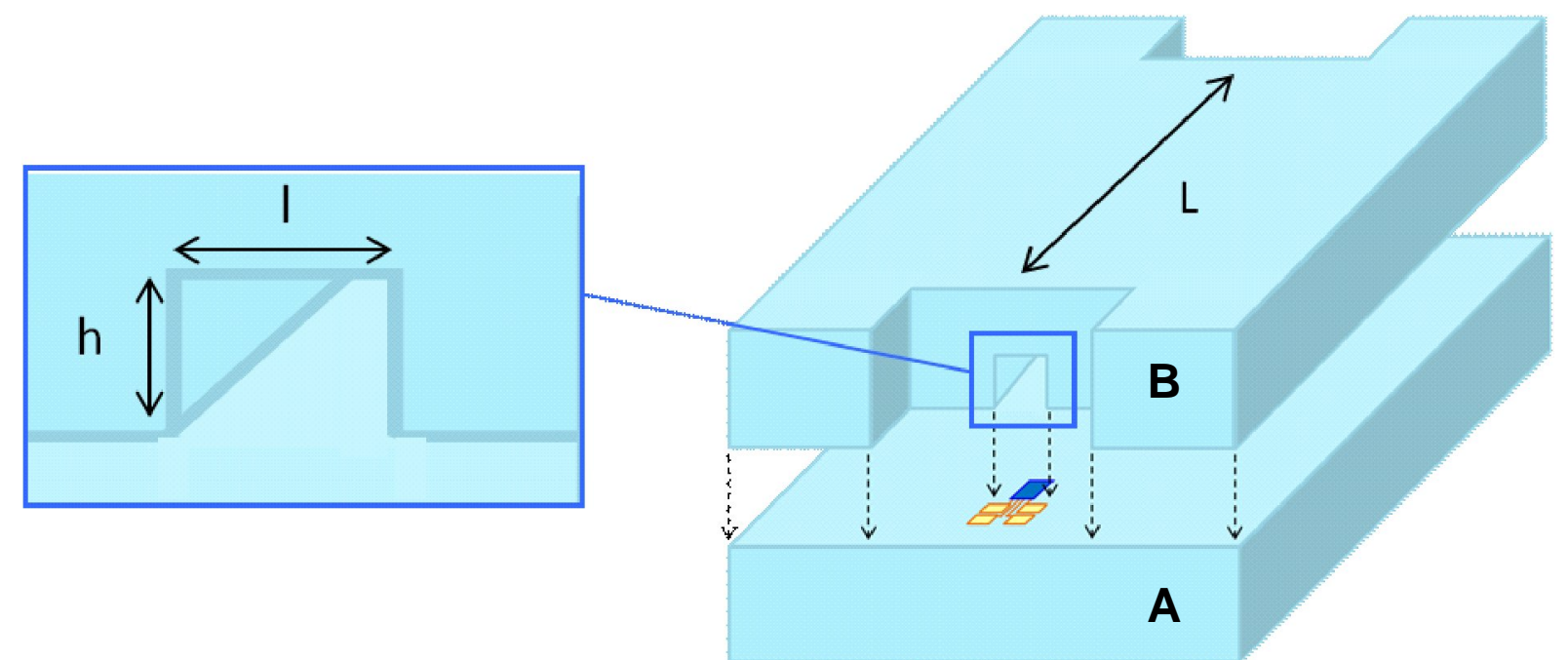


Figure 3

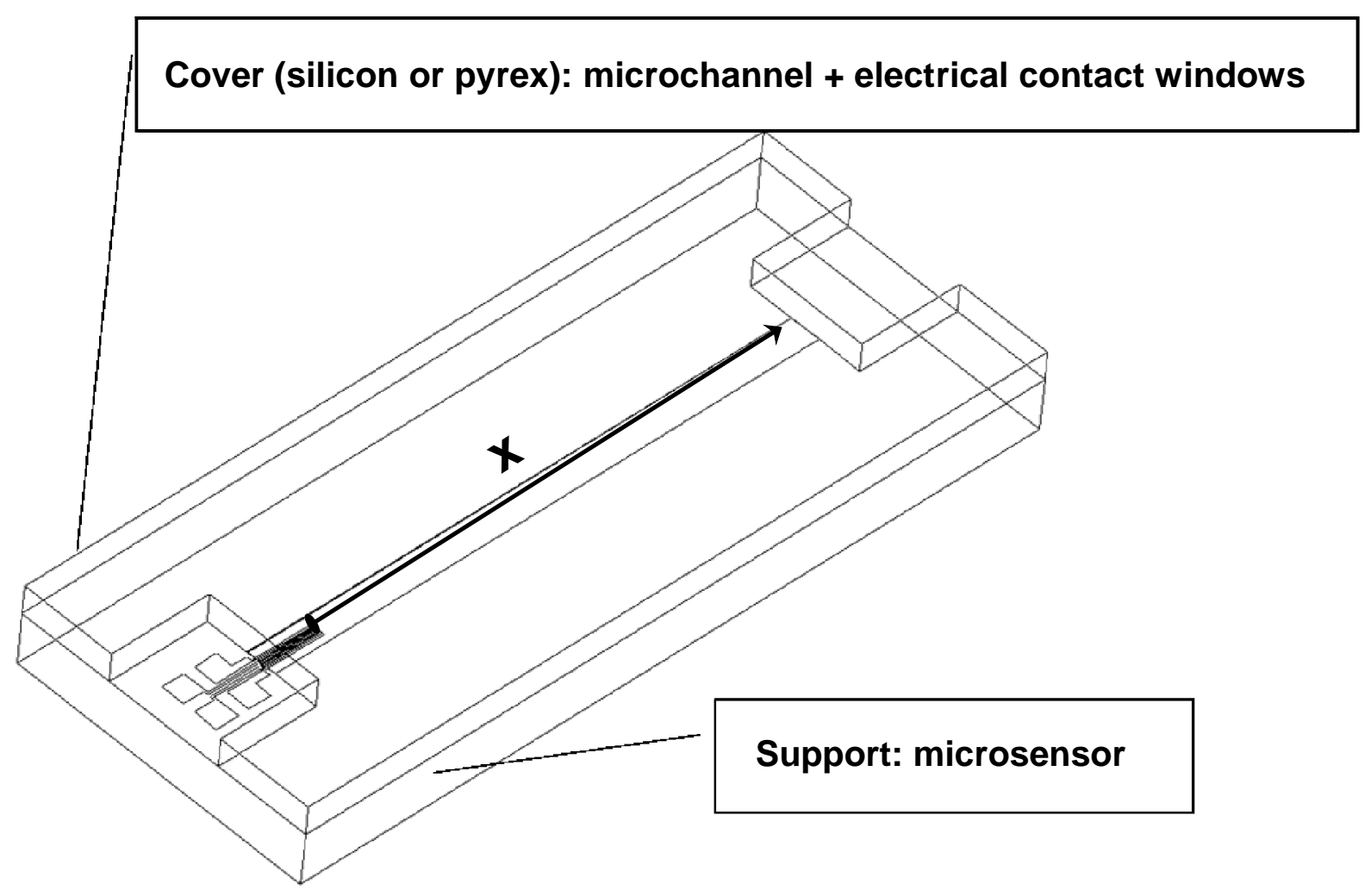


Figure 4

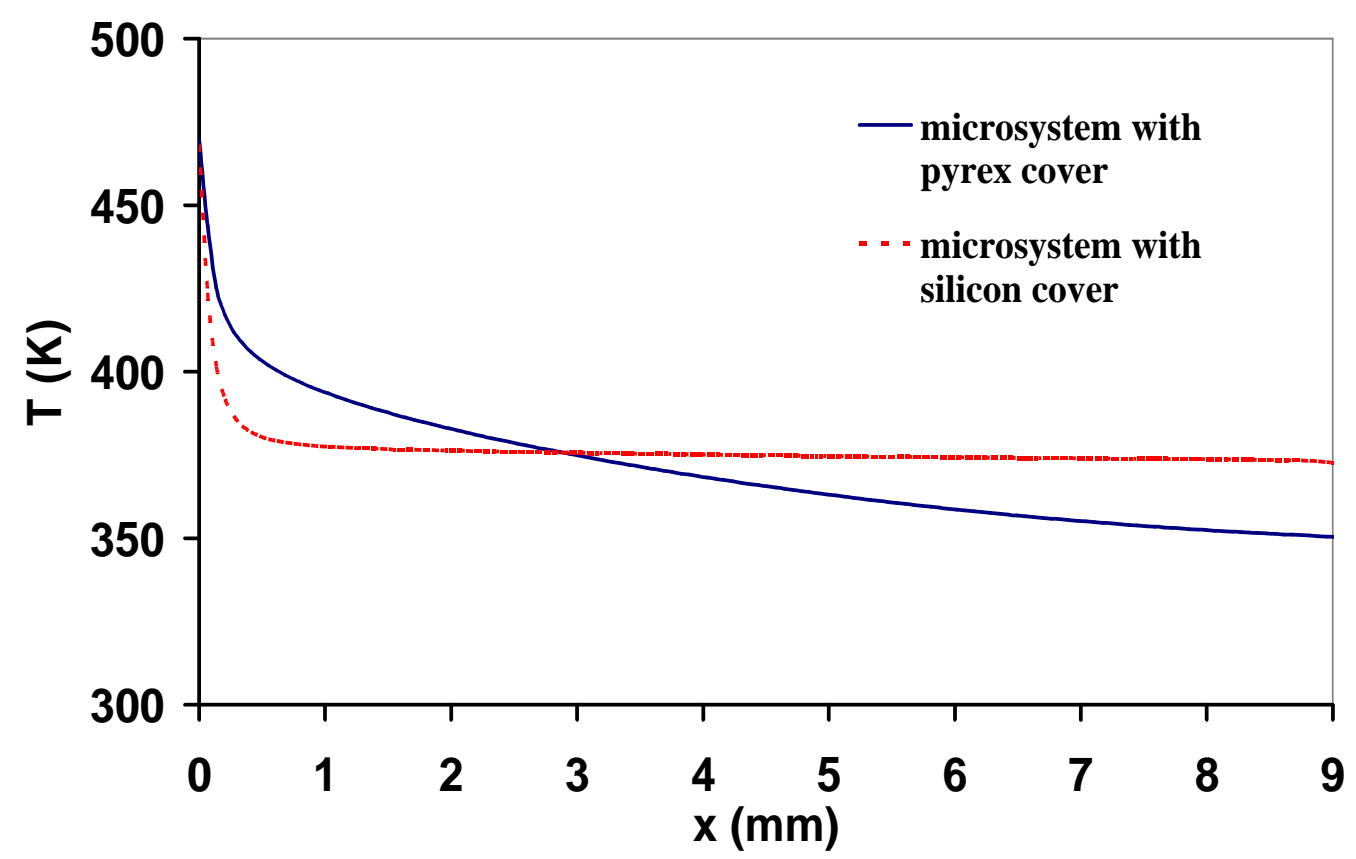


Figure 5

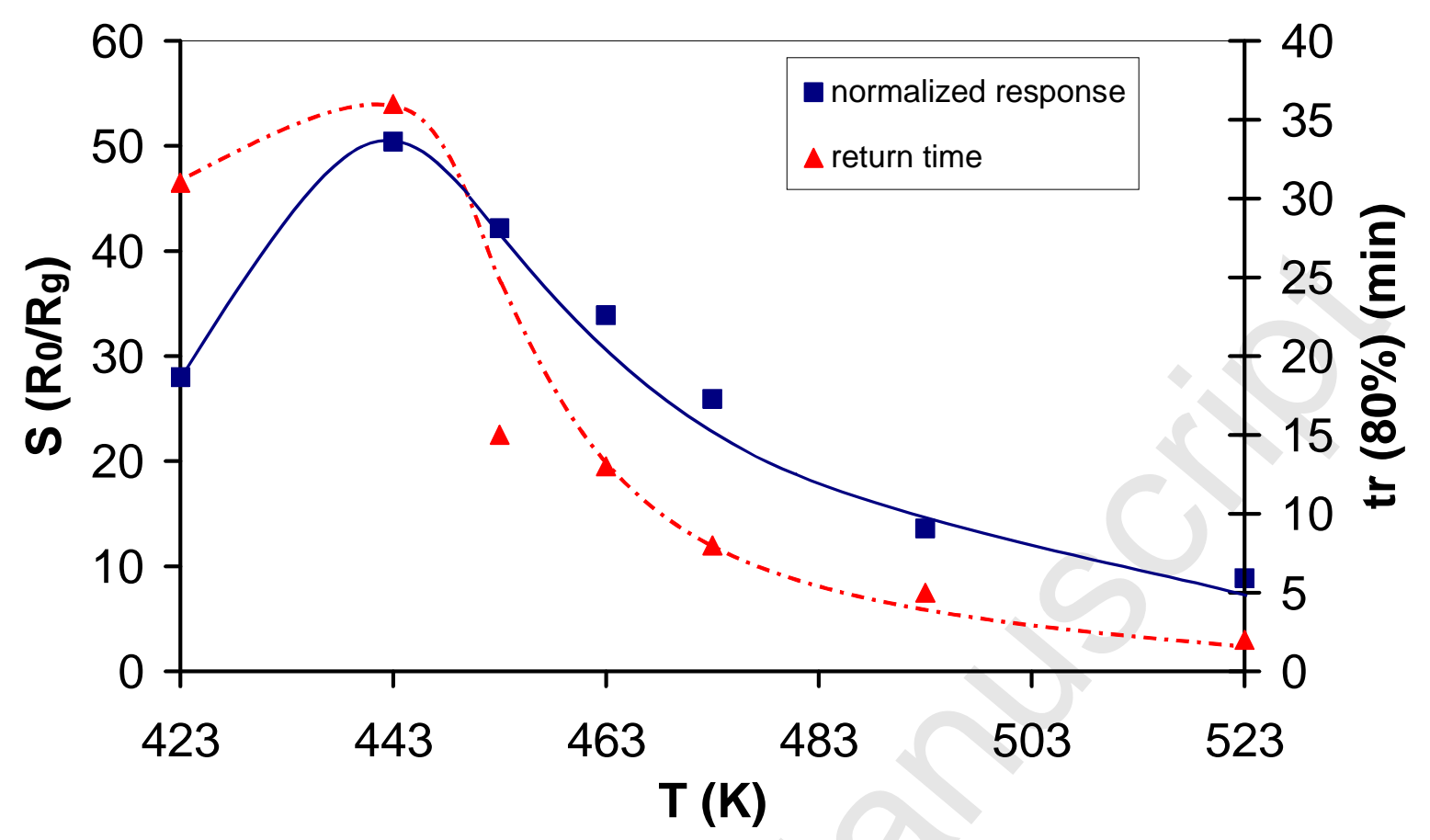


Figure 6

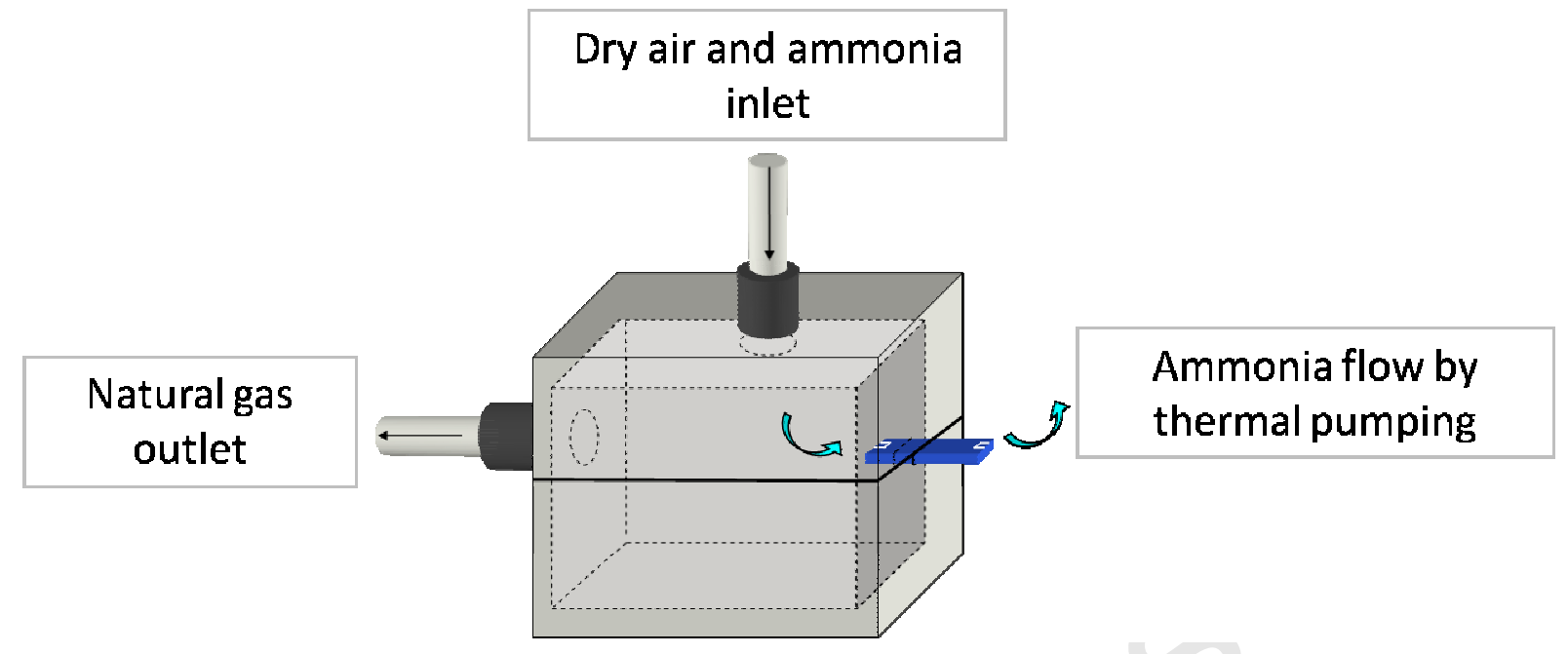


Figure 7

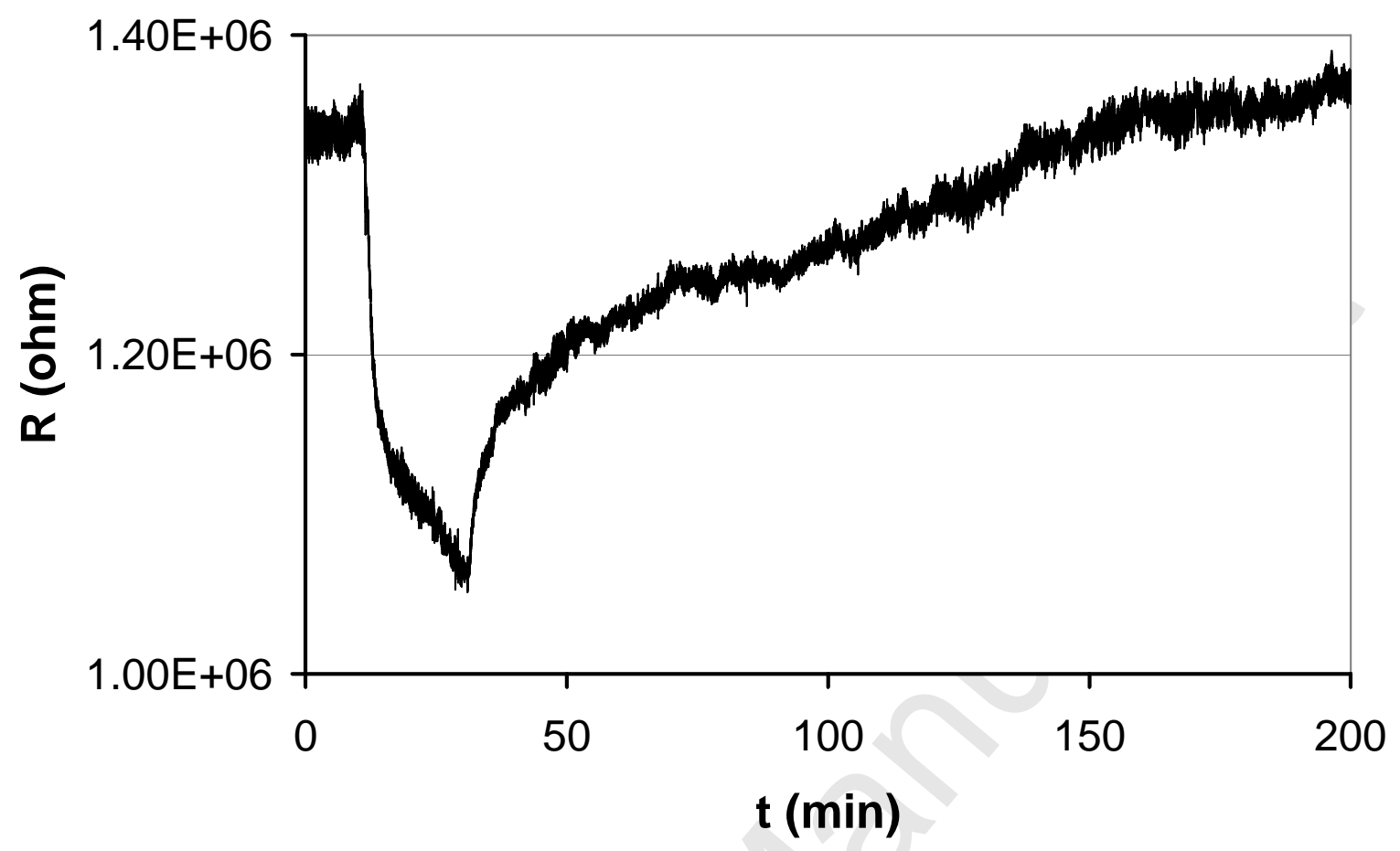


Ammonia detection by a novel Pyrex microsystem based on thermal creep phenomenon

\section{Highlights:}

- The design of a novel microfluidic system for gas analyses with an integrated pumping system is presented

- Thermal and mass flow rate device are simulated using Comsol Multiphysics software

- We characterized the microfluidic device in ammonia environment

- An experimental demonstration of thermal creep phenomenon was done 
Figure 1

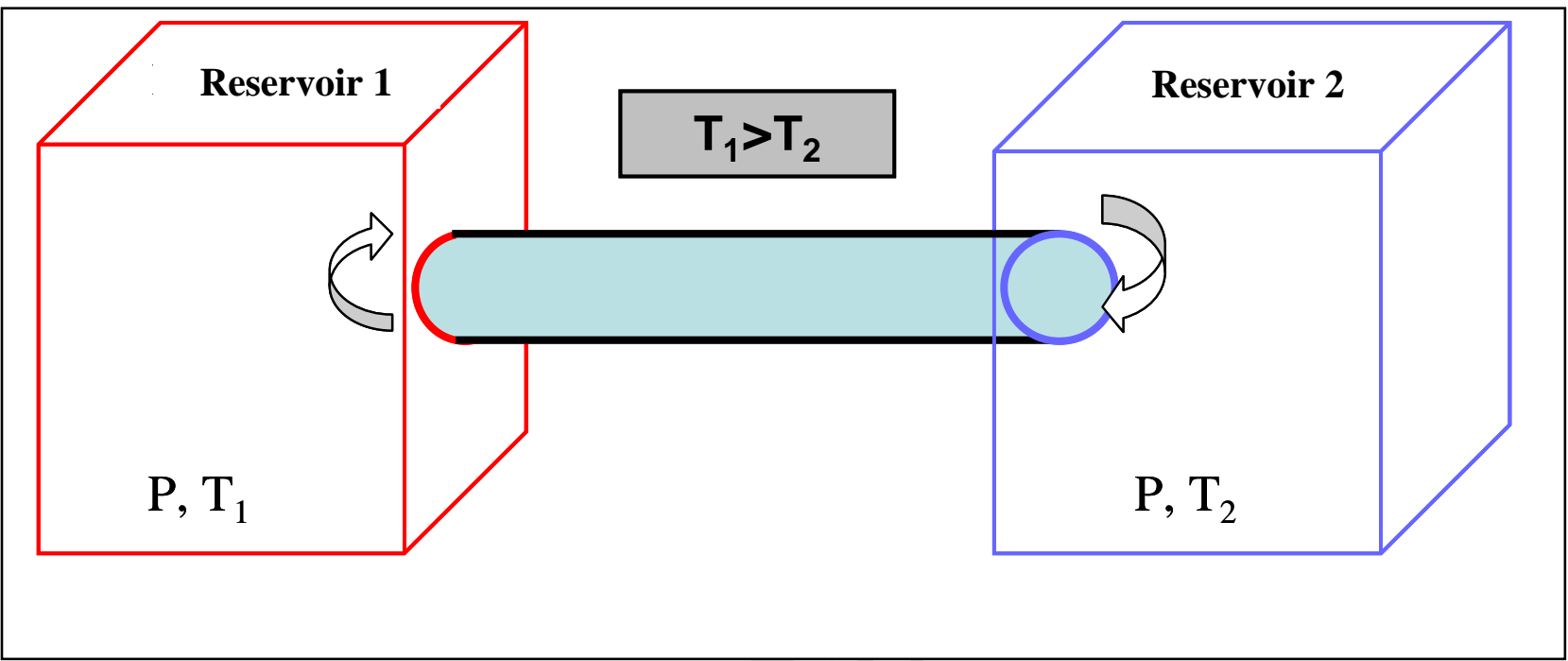

